$1-1-2013$

\title{
Your Smart Phones Are Hot Pockets to Us: Context Collapse in a Mobilized Age
}

Carolyn Marvin

University of Pennsylvania, cmarvin@asc.upenn.edu

Follow this and additional works at: https://repository.upenn.edu/asc_papers

Part of the Communication Commons

\section{Recommended Citation}

Marvin, C. (2013). Your Smart Phones Are Hot Pockets to Us: Context Collapse in a Mobilized Age. Mobile Media \& Communication, 1 (1), 153-159. https://doi.org/10.1177/2050157912464491 


\title{
Your Smart Phones Are Hot Pockets to Us: Context Collapse in a Mobilized Age
}

\begin{abstract}
A key guarantor of social trust and a necessary feature of democratic societies is a stable sense of social distance. Social distance is the cultural imaginary within which an individual's coordinates of social status and contingent social location allow or inhibit contact with similarly and dissimilarly located others. The rearrangement of customary social distances by new communication technologies is a source of considerable social anxiety. In mobile communication, this context collapse is instigated by a distinctive combination of affordances: deep connectivity, the accelerated speed and volume of communicative exchange, enhanced social legibility and asymmetric communicative transparency. Robust and effective levels of social trust depend on a political will to build strong democratic accountability and civil rights guarantees into emerging mobile architectures. Identifying specific recalibrations of familiar social distances by regimes of mobile communication and assessing the effects of these recalibrations in democratic terms is a central task of mobile research.
\end{abstract}

\section{Keywords}

asymmetric transparency, connectivity, context collapse, legibility, mobile communication, social distance, social trust

\section{Disciplines}

Communication | Social and Behavioral Sciences 
Your smart phones are hot pockets to us: Context collapse in a mobilized age

Carolyn Marvin University of Pennsylvania, USA

\begin{abstract}
A key guarantor of social trust and a necessary feature of democratic societies is a stable sense of social distance. Social distance is the cultural imaginary within which an individual's coordinates of social status and contingent social location allow or inhibit contact with similarly and dissimilarly located others. The rearrangement of customary social distances by new communication technologies is a source of considerable social anxiety. In mobile communication, this context collapse is instigated by a distinctive combination of affordances: deep connectivity, the accelerated speed and volume of communicative exchange, enhanced social legibility and asymmetric communicative transparency. Robust and effective levels of social trust depend on a political will to build strong democratic accountability and civil rights guarantees into emerging mobile architectures. Identifying specific recalibrations of familiar social distances by regimes of mobile communication and assessing the effects of these recalibrations in democratic terms is a central task of mobile research.
\end{abstract}

\title{
Keywords
}

asymmetric transparency, connectivity, context collapse, legibility, mobile communication, social distance, social trust

If I were to make a city plan, I think I would say, 'In what way can I make the architecture of connection which would enliven the mind as to how the availabilities can be even more enriched than they are?' Louis Kahn ${ }^{1}$

Special announcement for @circusbellyRT @Dronelnsertion DRONES WISH IT TO BE KNOWN: YOUR SMART PHONES ARE HOT POCKETS TO US. ${ }^{2}$

How do world-historical communication technologies change the human game on an epochal scale? By radically changing the social structure of knowledge, we might argue, and reconfiguring the deep tissue of our social arrangements. By that measure, the digital transformation unfolding at different velocities and levels of awareness around us is a game-changer. It has taken time to cross the threshold of visibility; it will chew up the old ways for a long time to come. Appreciating the scope of its impact, the multiplicity of its causes, its countertrends and uncertain consequences will take longer still. The chatter we offer about it along the way is a fascinating and sometimes comically deluded part of the process. My bit of chatter frames a piece of the story of interest to researchers: the broad recalibration of social distance that marks the current phase of the digital revolution, and the part of this recalibration that is chargeable to mobile. While the social core of digitization remains anchored in new forms of accessibility and transparency, mobile may be the First Big Thing to thrust digitization beyond the Vannevar Bushian dream of computing (1945) as the automated, large-scale extension of the worldhistorical technology formerly known as print.

Social distance is a powerful social fact. Each of us, members of interlocking, overlapping tribes, occupies social coordinates that register our relative exposure - how easily we can insulate ourselves, and alternatively, make ourselves accessible - to others who occupy coordinates of their own. Such locations flow from contingencies of class, strong and weak ties, role expectations, and technological affordance. They may be elastic or relatively fixed. They vary historically and across groups. Social distance is regulated across an inexhaustibly inventive range of barriers like bodyguards, firewalls and 
television screens. It is implemented in bureaucratic hurdles, surveillance operations, pecking orders, chains of command, invitation lists, professional and family networks, and all the other sorting devices that render us socially legible to one another. But mostly it is mediated by taken-for-granted norms that in the ordinary business of living allow some folks to come in close and keep others at a distance. The skillful navigation of the most freighted choreographies of approach and avoidance marks a wellsocialized individual. It also occupies an inordinate amount of human concern.

How we understand social distance goes well beyond calculation and convention, of course. It also has ideal and moral dimensions. Even when, pursuing ambition or justice or profit, or as an antidote to loneliness, we want social distances to be other than they are, we have in mind some concept of right proximity among intimates and strangers, citizens and government, consumers and corporations.

Though our sense of stability is rooted in the reliability of the social geography we inhabit, social distances change in the ebb and flow of group experience. Technology is a highly visible player in this process. When new forms put familiar social distances at risk, terrible anxieties ripple through the body politic. The formerly shielded find themselves exposed and vulnerable. Those with newly cleared paths to the once socially remote discover their new powers also bring unanticipated burdens. The precise unease generated speaks volumes about the meanings of the distances under siege. Michael Wesch's nervous metaphor, context collapse (2008), nicely captures the process I am describing. Originally applied to the dislocating effects of webcam interaction, it sums up the fears and opportunities that are now rising phoenix-like from the shattered foundations of pre-digital social distance.

That technology transforms social distances we are invested in is an old story. I recounted it for new forms of electrical communication in the late nineteenth century (Marvin, 1988). In the twentieth, broadcasting deposited socially distant worlds in domestic space, upending older codes of discretion and trust. New tolerances for intrusion had to be aligned with new ways to keep noxious invaders at arm's length. New conventions were devised to sort out the social environment into who was trustworthy and who was not.

Today social distance is both stretched and compressed by the solvent of binary code that makes every digital device connectible and visible to every other, at least in theory. This makes it possible to imagine universal networking - a socially intolerable condition. Perfect interactivity connects enemies as well as friends, mixes upstairs and downstairs, blurs public and private, and generates blueprints for both tyranny and democracy. As old boundaries crumble, culture and politics are busy constructing new modes of secrecy, publicness and exchange.

Digitally recalibrated social distance enters public consciousness through dramatic misfires. Popular media circulate shocking instances of social distance violated and high flyers brought digitally to heel. A deeply human fascination with breached social distance alerts us to new vulnerabilities (pedophiles that digitally reach into the home), humiliations (Anthony Wiener unintentionally, Charlie Sheen impulsively, Tyler Clementi undeservedly), and powers (mobilization for the Arab spring, narrowcast cruising, grassroots social commentary). New social hierarchies, new forms of openness and reticence, new etiquette styles and social obligations - all these emerge from context collapse.

What is at stake is social trust itself, the fragile conviction that our shared world is manageable and safe. What makes it so, at least in the communicative realm, is imagining that we are in perfect control of our accessibility and transparency. Today that confidence teeters precariously on the back of the mobility 
turn (Sheller \& Urry, 2006), weathering the storms and, seizing the opportunities presented by context collapse.

Four elements of context collapse emerging from mobile communication may be conceptualized as follows:

1. Deep connectivity: Because of convenience and low cost, mobile vastly amplifies the scale, volume and fluidity of digital activity. It likewise vastly multiplies modes of interactivity in personal and social media including microblogs and crowd-sourced applications. Digital and physical interfaces become denser, more complexly reticulated, more broadly distributed. Deep connectivity may be deployed to levy a kind of battering ram against siloization by authority: Sina Weibo lives; rebel Syrian groups document bodies in the streets against an official line. Beyond our ability to connect through video monitoring and other functions to more things and people than ever, deep connectivity provides a target-rich environment for things and people to monitor us as well.

2. Temporal acceleration: Activity and ease ramp up the digital pace in any number of fetishized forms including topic-trending, real time virality, coolfarming and coordinated swarming. Instant damage from tweetbombing, whether malicious or unintended, compromises tweeters as well as targets. Accountable time moves toward 24/7. Shrinking response time imperils the deliberative. Contrasting the relentlessness of social media with more thoughtful modes of civic exchange, the Mayor of New York observed, "We are basically having a referendum on every single thing that we do every day" (Grynbaum, 2012). Temporal acceleration can be overwhelming, as the besieged creator of Kony 2012 discovered. It takes toughness to ride the waves of fickle, foreshortened, crowd-sourced judgments in politics, culture and public policy, or to endure whiplash transformations of the personal into fodder for hordes of netizens (Think of the late, little mourned "Is Anyone Up?").

3. Expanded legibilities: Location-aware mobile makes explicit what used to be hidden or ambiguous. Mobile devices broadcast our journeys, our social networks, our idiosyncratic desires to observers with motives that may be at odds with our own (Mann, Nolan, \& Wellman, 2003). By ranking digital influence and participation, new aggregators of legibility (Klout, Yelp) create novel measures of social worth, performative obligations, and formats for surveillance (comically and chillingly elaborated in Gary Steyngart's prescient, acerbic Super Sad True Love Story [2010]). Citizens become marketing demographics in thrall to analytics for age, gender, attention, movement. While geo-tracking, mobile video and facial recognition increase options for navigation, aid and protection (searching for missing persons after dark, locating flame areas that endanger firefighters), they also pose opportunities for harassment and unprecedented threats to civil rights. Anticipating protests last year, San Francisco's Bay Area Rapid Transit (BART) pre-emptively shut down all mobile traffic on its premises. Mobile dragnets enabled by pliable service providers point to an alarming and growing official habit (Lichtblau, 2012). Drones for intelligence and killing abroad may be repurposed for facial recognition in domestic crowds and even weaponized for crowd control (Morley, 2012). 
4. Asymmetric transparency: Civility in the pre-mobile urban settlements of Jane Jacobs and Richard Sennett rested on anonymity and tolerance among co-present, mutually visible strangers. Public life built on this sturdy bourgeois understanding of cooperative difference is changing (De Waal, 2011). Mobile gated communities signal the advent of the "capsular" society (De Cauter, 2004). There is certainly convenience and safety in digital filtering. Grindr vaults handily over ambiguities of availability to pluck friends or sexual partners from anonymous, shared public space. But asymmetric transparency also tilts the surveillance advantage toward stalker/trackers and away from targets unaware of their own visibility. Consider the News of the World scandal, revealed for the first time in 2008, in which journalists repeatedly hacked the mobile voicemails of the famous and the unfortunate. According to the Crown Prosecutor, they acted with the knowledge of editors and executives and the collusion of the Metropolitan Police. Even digital savviness offers scant protection from software algorithms and actuated devices meant to steer consumption and other choices. The state's insatiable appetite for information about citizens digitally cast as the already- or soon-to-be-suspected shreds expectations for privacy. The lure of reduced force casualties makes predator drones, one of the darkest angels of assymetric transparency, more tempting to deployers, more ethically egregious, and often more ominous than weapons of mutually commensurate bodily proximity. At the least, drones violate the proportional violence and last resort tests of just war theory (Davies, 2011; Gregory, 2011).

Running through these examples is an Americentric focus on recalibrations of social distance in a new world of context collapse. Non-U.S., non-Western social distances and cultural logics are also fashioning unique and shared mobile affordances, opportunities, and dangers. International from the start, mobile research makes a number of these visible. A few exemplary studies may stand for the rest. Licoppe in France (2004) investigated how intimate relationships imagined as continuously connected by mobile render silence a source of anxiety. Soleil Archambault (2011) identified ratcheted-up opportunities for committing and discovering infidelity in Mozambique. Eriksson (2010) found heightened anxiety and rising expectations for assistance among mobile users of public safety answering services in Sweden. Pfaff (2010) explored how mobile-equipped Zanzibarian traders reduce work-related travel, expand buyer networks and seize opportunities for spur of the moment business, and how women whose movements in public space are restricted to communal religious observances use mobile to expand their sociability.

Back in the U.S., Evans-Cowley (2010) has surveyed the impact of mobile on urban movement and exploration. Gazzard (2011) argues that mobile reconstructs our very perceptions of the physical environment. Ling and McEwen (2010) examined conventions for managing simultaneously co-present and mediated others. Campbell and Kwak (2011) investigated what leads mobile users to engage with strangers in public. Curry, Phillips, and Regan (2004) looked at the "creeping legibility" of emergency response systems. Le Dantec and Edwards (2008) documented how an absence of mobile connectedness further estranges homeless citizens from family, employment and other systems of support.

Democratic social trust depends on many things, but much of its vitality and resilience will be determined for the future by how we manage deep connectivity, temporal acceleration, expanded legibilities, and asymmetric transparency. As old boundaries of public and private space wither, we must create a workable scope of social trust from new communicative forms by recourse to a deeper 
democratic politics. A vigorous response to the anxieties of context collapse means restraining the commercial and bureaucratic colonization of free human activity across an evolving landscape of embodied and disembodied spaces. It means resisting coercive manipulation by digital actors and surveillance by default - whether for profit or in the name of social order. It must regard with wariness the filter bubbles of digital gated communities, by turns heartless and paranoid. What is required above all are shared and visible commitments to dignified respect, obligations of care, and enforceable standards of public accountability for emerging digital architectures.

\section{Acknowledgements}

Special thanks to Sun-Ha Hong, who kept me alerted to the best examples of mobile communication research, and to Jeffrey Marvin and Cory Falk who were available for informative and stimulating conversations.

\section{Funding}

This research received no specific grant from any funding agency in the public, commercial, or not-forprofit sectors.

Notes

1. Lecture at the Pratt Institute, Brooklyn, 1973. http://marklow.blogspot.com/2004/09/fromlecture-atprattinstitute.html.

2. Dronelnerstion, Twitter, February12, 2012.

\section{References}

Bush, V. (1945). As we may think. Atlantic Monthly, 176(1), 101-107.

Campbell, S., \& Kwak, N. (2011). Mobile communication and civil society: Linking patterns and places of use to engagement with others in public. Human Communications Research, 37(2), 207-222.

Curry, M. R., Phillips, D. J., \& Regan, P. R. (2004). Emerging response systems and the creeping legibility of people and places. The Information Society, 20, 357-369.

Davies, S. (2011). Engineering \& Technology, 6(8), 38-40.

De Cauter, L. (2004). The capsular civilization: On the city in the age of fear. Rotterdam, The Netherlands: NAi Publishers.

De Waal, M. (2011). The urban culture of sentient cities: From an internet of things to a public sphere of things. In Shephard, M. (Ed.), Sentient city: Ubiquitous computing, architecture, and the future of urban space. Cambridge, MA: Architectural League of New York and The MIT Press.

Eriksson, M. ( 2010). Conceptions of emergency calls: Emergency communication in an age of mobile communication and prevalence of anxiety. Journal of Contingencies and Crisis Management, 18(3), 165174.

Evans-Cowley, J. ( 2010). Planning in the real-time city: The future of mobile technology. Journal of Planning Literature, 25(2), 136-149. 
Kwak, N., Campbell, S., Choi, J., \& Bae, S.-Y. (2011). Mobile communication and public affairs engagement in Korea: An examination of non-linear relationships between mobile phone use and engagement across age groups. Asian Journal of Communication, 21(5), 485-503.

Gazzard, A. (2011). Location, location, location: Collecting space and place in mobile media. Convergence: The Journal of Research Into New Media Technologies, 17(4), 405-417.

Grynbaum, M. (2012). Mayor warns of the pitfalls in social media. New York Times, March 21.

Gregory, D. (2011). From a view to a kill: Drones and late modern war. Theory, Culture \& Society, 28(78), 188-215.

Le Dantec, A., \& Edwards, W. K. (2008). Designs on dignity: Perceptions of technology among the homeless. $\mathrm{CHI}$ '08: Proceedings of the twenty-sixth annual SIGCHI conference on Human factors in computing systems (pp. 627-636).

Lichtblau, E. (2012). Cell carriers called on more in surveillance. New York Times, July 9.

Lemos, A. (2010). Post-mass media functions, locative media, and informational territories: New ways of thinking about territory, place, and mobility in contemporary society. Space and Culture, 13(4), 403-420.

Ling, R., \& McEwen, R. 2010. Mobile communication and ethics: Implications of everyday actions on social order. Nordic Journal of Applied Ethics, 4(2). Retrieved from http://individual.utoronto.ca/rmcewen/Publications/Ling McEwen.pdf

Mann, S., Nolan, J., \& Wellman, B. ( 2003). Sousveillance: Inventing and using wearable computing devices for data collection in surveillance environment. Surveillance and Society, 1, 331-355.

Morley, Jefferson (2012). The drones are coming -to America. Salon, April 10. Retrieved from: http://www.salon.com/2012/04/10/the drones are coming to america/

Pfaff, J. (2010). A mobile phone: Mobility, materiality and everyday Swahili trading practices. Cultural Geographies, 17(3), 341-357.

Sheller, M., \& Urry, J. (2006). The new mobilities paradigm. Environment and Planning A, 38, 207-226.

Soleil Archambault, J. (2011). 'Breaking up because of the phone' and the transformative potential of information in southern Mozambique. New Media \& Society, 13(3), 444-456.

Steyngart, G. (2010). Super sad true love story. New York, NY: Random House.

Wesch, M. (2008). http://mediatedcultures.net/projects/youtube/context-collapse/

\section{Author Biography}

Carolyn Marvin is the Frances Yates Professor of Communication at the Annenberg School for Communication at the University of Pennsylvania, Philadelphia. She is the author of When Old Technologies Were New: Thinking About Communication in the Late Nineteenth Century (New York: Oxford University Press, 1988), which in 2010 was named the \#1 book of the Top 50 Books in Technology by Atlantic Tech Canon, a division of The Atlantic Magazine. 
Corresponding author:

Carolyn Marvin, University of Pennsylvania, 3620 Walnut St., Philadelphia, PA 19146, USA

Email: cmarvin@asc.upenn.edu 